\title{
Lexis
}

Journal in English Lexicology

Book reviews | 2009

\section{Judith MUNAT, Lexical Creativity, Texts and Contexts}

John Benjamins Publishing Company, Amsterdam, Philadelphia, 2007, 294 pages

\section{Graham Ranger}

\section{(2) OpenEdition}

Journals

Electronic version

URL: http://journals.openedition.org/lexis/1705

DOI: $10.4000 /$ lexis. 1705

ISSN: 1951-6215

\section{Publisher}

Université Jean Moulin - Lyon 3

\section{Electronic reference}

Graham Ranger, "Judith munat, Lexical Creativity, Texts and Contexts », Lexis [Online], Book reviews,

Online since 05 January 2009, connection on 23 September 2020. URL : http://

journals.openedition.org/lexis/1705; DOI : https://doi.org/10.4000/lexis.1705

This text was automatically generated on 23 September 2020.

\section{(c) () (9)}

Lexis is licensed under a Creative Commons Attribution-NonCommercial-NoDerivatives 4.0 International License. 


\section{Judith MUNAT, Lexical Creativity, Texts and Contexts}

John Benjamins Publishing Company, Amsterdam, Philadelphia, 2007, 294 pages

\section{Graham Ranger}

\section{REFERENCES}

\section{Judith Munat}

Lexical Creativity, Texts and Contexts. John Benjamins Publishing Company, Amsterdam, Philadelphia, 2007. ISBN : 978-90-272-1567-3, Prix : $110 €, 294$ pages

$1 \quad$ Lexical Creativity, Texts and Contexts presents the papers resulting from a seminar on this theme held during the 2004 ESSE Conference in Zaragoza. It contains an editor's preface, a general introductory piece by Leonhard Lipka and eleven articles organised into four thematic sections: Lexical creativity in discourse, Lexical creativity in texts, Creative concept formation and Sociopolitical effects on creativity. Each article is accompanied by its own bibliographical references and the volume includes a full name and subject index. The hardback edition is handsomely presented, as one would expect from as experienced a publisher as John Benjamins. In the following review I will present and assess the contents of each article as it appears in the volume before concluding on the work as a whole.

2 Munat's editor's preface of three pages (xiii-xvi) explains briefly how the work arose and provides some indicators as to the organisation and the relevance of the opposition - which will return again and again the course of the volume - between creativity and productivity. Lipka's initial introduction, entitled "Lexical creativity, texuality and problems of metalanguage" (3-12), begins with a discussion of this opposition, the fundamental distinction being between rule-governed productivity and rule-changing creativity. After a number of methodological considerations, Lipka proceeds to present the articles individually, duplicating to some extent the editor's preface, albeit with 
further detail. He concludes that the articles in the present volume "will serve to illustrate that novel lexical items [...] depend not only on speaker intentions, context, co text, genre, TT or register (real or fictional) and audience-related factors but also on the topic, theme or domain as well as on extralinguistic reality [...] and audiencerelated factors" (10). As a non-specialist in lexicology, I confess I found Lipka's use of initialisms somewhat confusing (TTs, WF and ASDs correspond to "text-types", "wordformation" and "attention-seeking-devices", respectively) and some methodological distinctions (a binary opposition between serious and non-serious texts, for instance) rather surprising. Nonetheless, he is a prominent figure in lexicological research and this introductory piece serves to caution the value of the succeeding articles.

Hohenhaus, in "How to do (even more) things with nonce words (other than naming)" (15-38) focuses on nonce-formations. For Hohenhaus, the opposition between creativity and productivity can be formulated in terms of a cline, "reflected in different degrees of 'noteworthiness' of the formations in question: the outputs of rules at the more productive end of the scale tend to pass without much notice, while the more creative "coinages' tend to be more foregrounded" (16). He then goes on to provide an intriguing categorisation of the different functions of nonce-formations (other than their purely referential functions). The discussion that follows is stimulating, the analysis precise and the examples nicely chosen. Functions include deixis (debatably, in my view: "Let's go back to this vacation thing, right?" 19), hypostatisation (illustrated amusingly by hypermathematics or ultramahogany from Douglas Adams, the function of which is to " sound typical of SF" 22), attention-seeking (the coolometer). Particularly interesting functions are contrastive reduplication as in "the real spain spain, not your tourist spain" (25), ad hoc stereotypification as in "what a lot of hellos, howareyous, and whatareyouworkingons" (32), or emoting through conversion and reduplication in MUDs as in "'Anthony ohboys' or 'Pete actuallies"' (33). My personal favourite has to be the following example, included in Hohenhaus's Special cases, involving coded languageplay between two teenagers, quoted from Crystal (1998): “A: 'Look at the sizeness of it!' B: 'Cor, the sizenessness!'” (35)!

In "The phonetics of 'un-"' (39-57), Jen Hay considers the factors influencing the duration of the un- prefix in lexical derivations. As she rightly notes, "very little work has examined 'spoken morphology, investigating the way in which morphological structure is actually reflected in the phonetics of speech" (39). The corpus used is the ONZE (Origins of New Zealand English) corpus, featuring interviews with speakers born between 1850 and 1971. These choices in methodology and data allow her to draw two conclusions. Firstly, it would appear that the more recoverable the word is in the speaker's mental lexicon, the shorter the duration of the un- prefix will be (a word like unfortunate is more accessible than unburstable, say, or even than its base form fortunate). "Highly creative, productively coined un- words [...] are likely to reveal this productivity [or rather creativity, in the terms of the earlier definition!] in the relative length of the prefix" (54). Secondly, it would appear from the ONZE corpus that younger New Zealand English speakers tend to prefer to employ not + adjective sequences in preference to the un- prefix possibly, as Hay suggests, because "they are retrieving a greater proportion of their un- words whole", that is, younger speakers would appear to conceptualise un- words more often as whole units rather than as active derivations. Hay's study is interesting and original, if marginally outside the ambit of lexical creativity in the sense defined by Lipka. 
5 Antoinette Renouf, in "Tracing lexical productivity and creativity in the British Media" (61-89), presents a corpus-based study of lexical and phrasal neologisms over time, looking at the evolution of previously unused expressions. She studies the way in which a press-based neologism may or may not take off, according to what she terms 'inhibiting factors'. These include syntactic difficulties, foreign or classical terms, morphological limitations and topicality (here she cites the rise and fall of NIMBY and its derivates). She looks, more specifically, at the evolution of the expression 'Weapons of Mass Destruction' and variants, presenting the results graphically for greater clarity. The expression has generated a whole set of variants: weapons of mass *(e.g. of mass distraction / obstruction etc.), weapons of* destruction (e.g. of modest / scant destruction etc.) according, interestingly, to what Renouf qualifies as "a clear set of conventions" (74). She then provides case studies of a number of recent neologisms: chav, hoodie, neet and tsar (used with the new meaning of guru, supremo, pundit etc.) providing revealing collocational profiles for these terms. Her study is well presented and the methodological approach, in its use of corpora and collocational profiles, opens new and interesting possibilities for research in socio- and psycholinguistics.

6 "Cathy Wilcox meets the phrasal lexicon" is the curious title of Koenraad Kuiper's contribution (93-112). In this article, Kuiper looks at how Cathy Wilcox, an Australian cartoonist, exploits the idiosyncrasies of what he the author terms "phrasal lexical items" (or PLI's) to humorous effect. A PLI is defined as a lexical item with phrase structure. Kuiper gives a number of idiosyncratic properties of PLI's. He claims that the Get lost! cannot be transformed to *Get very lost!, unlike get annoyed, because Get lost! is a PLI, or that get on the bus is fine while get in the bus is not, because get on the bus is a PLI. These arguments are, for me, open to debate, in that they refuse to take into account the internal semantic composition of these groups. The impossibility of Get very lost! appears to me to be a function of the aspectual qualities of GET, LOST and the imperative. Kuiper's project is interesting, involving as it does questions of the relative recoverability of set expressions via, very often, the retroactive reconstruction of graphically represented stereotyped situations (the cartoons). However, I found his definition of PLI's too vague to be operational and his list of means by which PLI's may undergo "creative artistic deformation" (98) comes, I feel, too close to a catalogue at the expense of close analysis and explanation.

7 Adrienne Lehrer's catchily entitled “Blendalicious" (115-133) looks, as one would expect, at blending. After a brief definition of blends, she considers the structure of blends, remarking upon a useful semantic distinction between syntactic compounds and coordinate compounds. In syntactic compounds the blend presents a modifier-head construction, e.g. sci-fi, motel. Coordinate compounds "denote semantic elements from both entities" (119), e.g. beefalo. Blend splinters, Lehrer points out, can go on to become bound morphemes. Examples would be gate, originally from Watergate and now a suffix denoting some sort of a scandal, or the prefix Mc for "inexpensive, convenient, or easy but usually low-quality" (123) as in McMansions: "large, assembly-line houses in new developments" (123)! Lehrer briefly considers the psycholinguistic conditions for recognition and processing of novel blends, before presenting a number of thematic domains in which blending processes are particularly productive. Lehrer's article is certainly interesting and contains a wealth of original and often amusing examples (dogbella from dog + umbrella, frenemies from friends + enemies!). However, the very wealth of the data and the quasi-exhaustive ambitions of the article mean that Lehrer remains 
essentially descriptive, which is a shame, as many intriguing aspects of the material (recoverability, evolution, genre-dependence) would definitely have merited a more thorough exploration.

Paula López Rúa in "Keeping up with the times: lexical creativity in electronic communication" (137-159) offers "a survey of common methods and sources of lexical creativity" in text messaging and on-line communication. Text-messaging relies on initialism (Rúa employs "initialisation") along the lines of ASAP or SWALK, abbreviation, often omitting vowels ( $p l s, s p k, h v$ for please, speak, have etc.) and, more interestingly, I feel, the use of certain letters and numbers as phonetic shorthand as in 2gthr, 4U, L8r (together, for you, later) etc. Apparently there also exists an 'advanced' texting code, recommended by guidebooks, which implies a number of norms and allows Rúa to propose advanced texting sentences such as 2DAsYaLkEDA ("today's your lucky day")! The prescriptivism of this form of texting might well be rejected by the predominantly youthful users, as Rúa rightly notes, following Crystal (2001). Rúa moves on to Netspeak, considering, as the title has it, "hackers, crackers, bloggers, Usenetters, websters and other netizens" (144). She includes a large number of often amusing examples, but I feel that the declared intention to deal with Netspeak is doomed to become a list, given the very diversity of forms of linguistic communication to be found on the Net. A blogger and a hacker do not communicate in the same circles, nor in the same way! She remarks in conclusion that the motivation for lexical innovations is pragmatic, ludic and sociolinguistic. Rúa's article forms a useful short introduction to the area, but I again found myself thinking that deeper study of a specific corpus of electronic communication might have led to a more stimulating discussion. The socioand psycholinguistic motivations behind lexical innovation on-line represent a particularly fertile area for future research, in my view.

"Lexical creativity as a marker of style in science fiction and children's literature" (163-185), by the volume editor, Judith Munat, makes a study of novel word formation in Philip K. Dick's The Simulacra and Roald Dahl's The BFG in a spirit similar to Hohenhaus's contribution earlier on. The diversity of word formation processes leads her to ask ""in what way [...] the context condition[s] lexical creativity" (164). A brief discussion of the productivity / creativity opposition leads her to state, drawing on Bauer (2001), that "creative coinages [...] change the rules [creativity] while rulegoverned coinages exploit the rules [productivity]" (165). Munat's survey of coinages in her two novels and in other works taken from the same genres shows that "creative formations are less rule-breaking than might initially be thought, often a matter of degree, and, especially when viewed in relation to their textual environments, are neither weird nor eccentric" (168). Munat's study comes, I feel, closer to the remit defined by the title of the collection, "Lexical Creativity: Texts and Contexts", in that she does indeed refer relevantly to the factor of context, unlike a number of more statistical, or classificatory articles in the same volume.

Tony Veale's article, "Dynamic creation of analogically-motivated terms and categories in lexical ontologies" (189-212), considers the conditions by which new lexical analogies are created, arguing that the combination "Hebrew-Deity", for example, arises from an analogical chain of reasoning of the type: "Hebrew-Deity is to GreekDeity, what Hebrew-Alphabet is to Greek-Alphabet". His article attempts to provide a formal logico-semantic model for the generation of such lexical analogies. Veale adopts a computational model of representation which I am not sufficiently familiar with but, 
as I understand it, the conditions for new modifier-head combinations are shown to be calculable as a function of the individual combinational possibilities (or affordances) of the modifier and the head in question. The hypothesis is tested with some success using WordNet, although the detail of the computer implementation of the logical calculus is unfortunately not made explicit. Veale's article is interesting, albeit unexpected and untypical of the collection, for two reasons. Firstly, it requires the reader to possess a fair grounding in logical reasoning to understand its implications. Secondly, as Veale himself points out, his perspective on lexical creativity is very different from that of the other articles of the collection since he considers creativity in the broadest, Chomskyan sense of the term as "the potential of human language to generate [...] an unlimited number of valid word combinations" (209).

11 "Creative lexical categorisation in a narrative" (213-236) by Ma Dolores Porto takes as its corpus a fantasy novel in which practically all the characters possess magical powers, and observes how readers interpret the nonce formations and neosemes in the novel using strategies of lexical recategorisation which, Porto hypothesises, must be similar to those used for interpretation in everyday language use. Porto adopts the prototypical approach to categories found in cognitive linguistics to look, for example, at how the term Dead, in the chosen fantasy novel, undergoes a recontextualisation via semantically anomalous uses which enable the reader to understand that here it means without magical powers. The lexical field of wizards and other magi is much richer, in the novel, than in everyday life, and so new words are invented (on the basis of existing resources of word-formation, it must be said) while existing words acquire more specialised meanings (neosemes). She then goes on to look at how human motion verbs are similarly recategorised in a fantasy world where people habitually float, rather than walk! Although Porto's article remains descriptive, providing few answers, it does nonetheless pose useful questions about how speakers manage to interpret and recontextualise newly encountered words in their everyday linguistic use, without even being aware of the process. Within the texts and contexts framework defined by the collection title, it is a little disappointing that Porto chooses not to give further consideration to the readership of this type of fantasy novel.

12 Andrejs Veisbergs, in "Occasional and systematic shifts in word formation and idiom use in Latvian as a result of translation" (239-261) suggests that, since the 1990's, the Latvian tongue has seen an increase in creative processes thanks to previously absent, or highly censored, contact with other languages, and particularly English. Veisbergs' main contention is that "a more open linguistic policy brought about [...] a more colloquial style in the media and freer use of substandard lexis in printed media (formerly taboo language)" (247). The article presents a relatively little known area of linguistic research and provides us on the way with some revealing figures. We learn, for instance that, in 1985, 209 books were translated into Latvian, including 140 books from Russian, and only 9 from English. In 2004, 679 books were translated into Latvian, 68 from Russian, and 359 from English. Veisbergs also charts the success of the expression a skeleton in the cupboard (closet, I would have said) which, from being previously unknown in Latvian, has in no time become a fully-fledged Latvian expression employed in a variety of forms in the media. Broadly speaking, however, the article lacks a firm methodological basis and far too often slips into anecdotal evidence and illustration where I personally would have preferred a fuller discussion of the issues involved. 

"Critical creativity" in "A study of 'politically correct' terms in style guides for different types of discourse" (263-282). She aims to study the "interrelations between lexical creativity, language policy and the discursive domain" (263) considering politically correct terms as examples of lexical creativity. The style manuals she draws on are for institutional and official use (UNESCO etc.), academic use (MLA etc.) and media language (Times and Guardian). She then compares the different guides quantitatively (how much advice is given and how many terms are censured) and qualitatively (what sorts of terms are targeted). Three main patterns for creative word-formation appear: unification, specification and euphemism. Unification involves the suppression of (essentially gender-) differences through non-sexist umbrella terms (e.g. poet for poet and poetess, humanity instead of mankind). Specification involves more detailed descriptions of "characteristics regarding ethnicity, age, gender and other traits" (277) (e.g. girl for women under 18 and elderly for those over 65). Euphemism involves replacing terms judged to be pejorative by more neutral terms (Inuit for Eskimo, mixed race or nonwhites for half-caste etc.). In her conclusion, Fischer briefly compares the different areas of interest of the style guides. She concedes that "the suggestions given do not seem to be very creative, since they are mostly recasting of existing expressions" (280) (or neosemes, to use a term taken from Porto's article). The idea of taking style guides to see what they might reveal to us about language use and how their recommendations might be creative opens an interesting domain of research. It seems to me that further work is required to distinguish the themes and the types of guide according to their intended target readership.

All in all, Lexical Creativity, Texts and Contexts and Contexts presents the reader with a thought-provoking collection of generally original articles on contemporary issues in lexicology. One might find the diversity of themes and the absence of a common theoretical approach initially unsettling. It is however an inevitable consequence of a collection resulting from an international workshop of this type and might also be considered a strength, as a wealth of methodological perspectives which might otherwise have evolved in isolation are brought together in one place and in one rewarding volume.

\section{BIBLIOGRAPHY}

BAUER Laurie, Morphological Productivity, Cambridge: Cambridge University Press, 2001.

CRYSTAL David, Language Play, London: Penguin, 1998.

CRYSTAL David, Language and the Internet, Cambridge: Cambridge University Press, 2001. 


\section{AUTHORS}

\section{GRAHAM RANGER}

Graham Ranger, Department of English, Université d'Avignon et des Pays de Vaucluse, France. Graham Ranger, Department of English, Université d'Avignon et des Pays de Vaucluse, France. Graham Ranger works as a senior lecturer at the Université d'Avignon et des Pays de Vaucluse where he teaches primarily English Linguistics and Translation. His study of operations of readjustment and reappraisal in authentic texts has contributed to his interest in many of the issues addressed in Lexical Creativity, Texts and Contexts. 